\title{
Association of postoperative blood pressure and bleeding after cardiac surgery
}

\author{
David McIlroy, MBBS, MClinEpi, FANZCA, ${ }^{\mathrm{a}, \mathrm{b}, \mathrm{c}}$ \\ Deirdre Murphy, MBBChBAO, MRCPI, FCARCSI, FCICM, ${ }^{\mathrm{d}} \mathrm{Jessica}_{\mathrm{Kasza}} \mathrm{PhD},{ }^{\mathrm{e}}$ \\ Dhiraj Bhatia, MBA, BSc, ${ }^{a}$ and Silvana Marasco, PhD, MBBS, MSurg, MBioethics, FRACS ${ }^{f, g}$
}

\section{ABSTRACT}

Objective: We sought to characterize the relationship between postoperative blood pressure on the day of surgery and metrics of bleeding.

Methods: In a preplanned secondary analysis of prospectively collected data from the Limiting IV Chloride to Reduce AKI trial (NCT02020538), univariate and multivariable regression analyses explored the association between peak systolic blood pressure, peak mean arterial pressure, and peak central venous pressure recorded postoperatively on the day of surgery and multiple metrics of bleeding. Patients at increased bleeding risk due to specific criteria were excluded from analysis. The primary outcome was chest tube drainage (milliliters per hour) on the day of surgery. Secondary outcomes included red blood cell transfusion, surgical re-exploration for bleeding, and hospital mortality.

Results: The study cohort comprised 793 patients. Mean \pm standard deviation peak systolic blood pressure, mean arterial pressure, and central venous pressure were $125 \pm 15 \mathrm{~mm} \mathrm{Hg}, 83 \pm 9 \mathrm{~mm} \mathrm{Hg}$, and $12 \pm 4 \mathrm{~mm} \mathrm{Hg}$, respectively. Median (interquartile range) chest tube drainage on the day of surgery was $33 \mathrm{~mL} / \mathrm{hour}$ (interquartile range, $23 \mathrm{~mL} /$ hour-51 mL/hour). Adjusted for prespecified variables, there was no positive association between peak systolic blood pressure and bleeding outcomes, including chest tube drainage $(-2.2 \mathrm{~mL} / 10 \mathrm{~mm} \mathrm{Hg}$; $95 \%$ confidence interval, -3.9 to $-0.5 \mathrm{~mL} / \mathrm{h} / 10 \mathrm{~mm} \mathrm{Hg} ; P=.01$ ) or volume of transfusion $(-15 \mathrm{~mL} / 10 \mathrm{~mm} \mathrm{Hg} ; 95 \%$ confidence interval, -29 to $-1 \mathrm{~mL} /$ $\mathrm{h} / 10 \mathrm{~mm} \mathrm{Hg} ; P=.04)$. Results remained broadly consistent across multiple secondary outcomes and regardless of whether systolic blood pressure or mean arterial pressure was the explanatory variable.

Conclusions: The lack of positive association between peak systolic blood pressure or peak mean arterial pressure with metrics of bleeding after cardiac surgery promotes equipoise for testing the influence of higher blood pressure targets during the early postoperative period. (J Thorac Cardiovasc Surg 2019;158:1370-9)

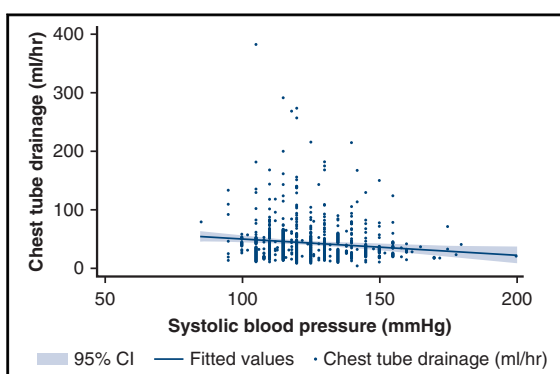

Chest tube drainage versus peak systolic blood pressure on postoperative day 0 .

Central Message

The lack of association between increasing peak SPB or MAP with increased bleeding after cardiac surgery promotes equipoise for testing higher blood pressure targets during the early postoperative period.

\section{Perspective}

Concern for a potential increase in bleeding with higher blood pressure may limit use of a higher target blood pressure as strategy to prevent perioperative end-organ injury after cardiac surgery. Lack of positive association between peak postoperative SBP or MAP and bleeding in the study cohort promotes equipoise for testing the influence of higher blood pressure targets early after cardiac surgery.

See Commentaries on page 1380 and 1382.
From the Departments of ${ }^{\mathrm{a}}$ Anaesthesia and Perioperative Medicine and ${ }^{\mathrm{f}}$ Surgery, and the ${ }^{\mathrm{d}}$ Intensive Care Unit, Alfred Hospital, Melbourne, Victoria, Australia; ${ }^{\mathrm{c}}$ Department of Anesthesiology, Vanderbilt University, Nashville, Tenn; Departments of ${ }^{\mathrm{b}}$ Anaesthesia and Perioperative Medicine, ${ }^{\mathrm{e}}$ Epidemiology and Preventive Medicine, and ${ }^{\mathrm{g}}$ Surgery, Monash University, Melbourne, Victoria, Australia.

Jointly funded by grants from the Australian and New Zealand College of Anaesthetists (14/010) and the Society of Cardiovascular Anesthesiologists/International Anesthesia Research Society (2014).

Received for publication March 20, 2018; revisions received Nov 12, 2018; accepted for publication Jan 12, 2019; available ahead of print March 8, 2019.

Address for reprints: David McIlroy, MBBS, MClinEpi, FANZCA, Department of Anesthesiology, Vanderbilt University, Suite 526, Medical Arts Building, 1211 21st Ave S, Nashville, TN 37212 (E-mail: david.r.mcIlroy@vumc.org). 0022-5223/\$36.00

Copyright (c) 2019 by The American Association for Thoracic Surgery https://doi.org/10.1016/j.jtcvs.2019.01.063
With an estimated incidence between $20 \%$ to $30 \%$ acute kidney injury (AKI) remains a major burden after cardiac surgery, associated with increased short and long-term morbidity, mortality, and cost. ${ }^{1-4}$ Although the etiology of cardiac surgery-associated AKI is likely multifactorial,

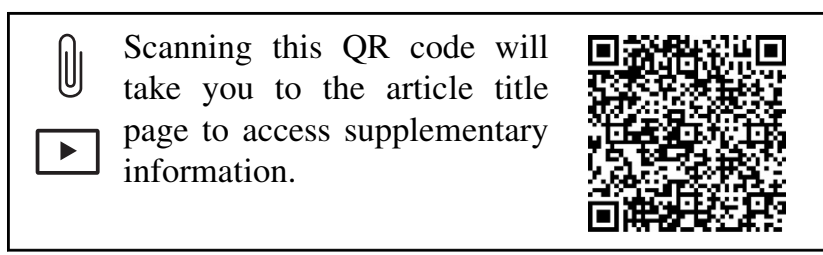




\section{Abbreviations and Acronyms \\ AKI = acute kidney injury \\ ATACAS $=$ Aspirin and Tranexamic Acid for \\ Coronary Artery Surgery \\ $\mathrm{CPB}=$ cardiopulmonary bypass \\ $\mathrm{CTD}=$ chest tube drainage \\ $\mathrm{CVP}=$ central venous pressure \\ ICU = intensive care unit \\ LICRA $=$ Limiting IV Chloride to Reduce AKI \\ MAP $=$ mean arterial pressure \\ pRBC $=$ packed red blood cells \\ SBP $=$ systolic blood pressure}

relative hypoperfusion of the kidneys has been suggested as a contributing factor. ${ }^{5-7}$

A joint international consensus statement from the American Thoracic Society, the Society of Critical Care Medicine, and others on the prevention and management of acute renal failure in intensive care patients recommends targeting a mean arterial pressure (MAP) $\geq 65 \mathrm{~mm} \mathrm{Hg}$ in most patients with shock, or higher if patients have a history of hypertension. ${ }^{8}$ A European Society of Intensive Care Medicine working group for nephrology recommend individualizing target blood pressure where possible to prevent renal injury in intensive care units, especially where knowledge of premorbid blood pressure is available. ${ }^{9}$ Consideration of a higher target blood pressure in these settings likely reflects the expected rightward shift in the renal autoregulatory curve that occurs with chronic hypertension, ${ }^{10}$ a frequent comorbidity in patients undergoing cardiac surgery. Additional blunting of autoregulation that occurs in the setting of evolving renal injury ${ }^{8}$ may further increase the risk of relative renal hypoperfusion in the setting of a seemingly normal postoperative perfusion pressure.

Although less frequent than AKI, neurologic injury such as stroke may be a devastating complication after cardiac surgery. Like AKI, relative hypotension is suggested as a contributory factor, ${ }^{11,12}$ and a higher perioperative target blood pressure may offer a potential mitigating strategy in at-risk patients such as those with preexisting hypertension or flow limiting cerebrovascular stenoses. ${ }^{11}$

Nevertheless, concern over bleeding from vascular anastomoses and other suture lines in the early postoperative period mean clinicians are understandably wary about the risk of increasing blood pressure after cardiac surgery. There is little evidence currently available to inform the upper limit of blood pressure that may be safely targeted during the early postoperative period without increasing bleeding and associated risks. Addressing this current knowledge gap may help provide the clinical equipoise necessary to design and conduct clinical trials testing the effect of targeting higher blood pressure during the early postoperative period on AKI and adverse neurologic outcomes. We therefore undertook a preplanned secondary and exploratory analysis of the Limiting IV Chloride to Reduce AKI (LICRA) ${ }^{13}$ clinical trial database with the aim of testing for evidence of a positive association between the upper limits of systolic blood pressure (SBP), MAP, and central venous pressure (CVP) recorded postoperatively on the day of surgery (postoperative day 0 ) with chest-tube drainage, transfusion of packed red blood cells (pRBC), unplanned surgical re-exploration for bleeding, and mortality.

\section{METHODS}

\section{Study Design and Participants}

The LICRA trial protocol was approved by our institution's Human Research and Ethics Committee (project No. 382/13) and registered with www.ClinicalTrials.gov (NCT02020538). It has been previously described in detail. Briefly, it was an investigator-initiated, single-center, open-label, 4-period, pragmatic controlled clinical trial testing the influence of a comprehensive policy aiming to control the chloride load from all intravenous fluid administered both intraoperatively and postoperatively in an intensive care unit (ICU) to patients undergoing cardiac surgery. The study protocol was applied to all patients undergoing cardiac surgery from February 3, 2014, through December 20, 2015. Patients younger than age 18 years or requiring preoperative renal replacement therapy at the time of surgery, undergoing combined cardiac surgery and renal transplantation, or sufficiently minor surgery to not require postoperative ICU admission were excluded from data collection and analysis. Patients undergoing repeat surgery during the course of the study were analyzed only once, according to the fluid strategy employed during their index surgery. Due to the nature of the study and the fact that all intravenous fluids included in the study protocol were readily available for clinical use, the requirement for preoperative written informed consent from each patient was waived. Results of the primary analysis from 1136 patients have been published, finding no evidence that a perioperative strategy to limit intravenous chloride administration influenced short-term renal outcomes or mortality. ${ }^{13}$

The current study was a preplanned secondary analysis exploring the relationship between hemodynamic parameters in the early postoperative period and metrics of bleeding. Clinical management of each patient's hemodynamic state, including administration of blood products and surgical re-exploration, was entirely at the discretion of treating clinicians. Although a strict transfusion policy was not enforced senior clinicians within our institution typically use a haemoglobin threshold of approximately $7 \mathrm{~g} / \mathrm{dL}$ to guide transfusion in patients not actively bleeding. The study cohort was defined as the original LICRA cohort with exclusion of patients undergoing surgery for transplantation or the presence of a ventricular assist device; extracorporeal membrane oxygenation; or intra-aortic balloon pump preoperatively, at completion of surgery, or any stage on postoperative day 0 . Patients with preoperative platelet count $<100 \times 10^{9} / \mathrm{L}$, international normalized ratio $>1.3$, or missing data for either of these variables were also excluded, as were patients with recent (or unknown) exposure to clopidogrel within 5 days preoperatively or other anticoagulant drugs (eg, dabigatran) within 7 days preoperatively. Primary outcome and explanatory variables were prospectively recorded in the main LICRA database.

\section{Outcome Measures}

The primary outcome was chest tube drainage (CTD) on postoperative day 0 , defined as total CTD recorded by nursing staff in the ICU chart for postoperative day 0 divided by number of hours from postoperative ICU admission through midnight on the day of surgery. Management of chest 
drains was standardized for clinical practice throughout the study (Pleurevac system [Teleflex, Sydney, Australia]; $-20 \mathrm{~cm}$ water suction unless otherwise directed by medical staff) thus minimizing variation in tube management. Secondary outcomes included CTD corrected for body weight, postoperative administration of $\mathrm{pRBC}$ from ICU admission through the end of postoperative day 1 or ICU discharge, whichever occurred first, unplanned surgical re-exploration for bleeding before completion of postoperative day 1, and hospital mortality. Only surgical re-exploration confirmed on manual review as having been performed for potential bleeding and unplanned at the time of index surgery was included in the numerator for this outcome.

\section{Explanatory Variables}

The primary exposure variables of interest were peak SBP, peak MAP, and peak CVP recorded in the ICU chart postoperatively on the day of surgery. To avoid capturing very brief or transiently elevated pressures that may be of limited clinical significance, we prespecified collection of the second highest value recorded on postoperative day 0 for each of these parameters. In view of potential for the second-highest value of a given hemodynamic parameter to be less than the second-lowest value for the same parameter, particularly when volume or range of recorded data was limited, such anomalies were screened for and, where identified, data for that variable was excluded from analysis. For simplicity these hemodynamic variables are referred to as peak SBP, peak MAP, and peak CVP throughout the remainder of the study.

\section{Statistical Analysis}

Distribution of CTD, pRBC transfusion, and hemodynamic parameters were initially characterized and reported as mean \pm standard deviation, median (interquartile range) (IQR), or count (proportion). Baseline characteristics were characterized according to quartiles of CTD. The relationship between each of peak SBP, MAP, and CVP with CTD was explored using fractional polynomials for evidence of inflection points that would make further nonlinear exploration most appropriate. Univariate and multivariable regression analyses then explored the relationship between these early postoperative hemodynamic parameters and various metrics of bleeding and hospital mortality, using linear and logistic modeling techniques for continuous and dichotomous outcomes, respectively. Based on existing knowledge and expert opinion, covariates included in the multivariable analysis were age, gender, previous cardiac surgery, surgical procedure, case urgency, preoperative estimated glomerular filtration rate $<60 \mathrm{~mL} /$ $\min / 1.73 \mathrm{~m}^{2}$, recent preoperative exposure to aspirin or low molecular weight heparin, duration of cardiopulmonary bypass (CPB), assigned treatment group in the primary LICRA study, and coenrollment in the contemporaneous Aspirin and Tranexamic Acid for Coronary Artery Surgery (ATACAS) trial, a randomized trial of tranexamic acid in coronary surgery. ${ }^{14}$ Various sensitivity analyses were conducted, exploring the effect of additionally adjusting for variables strongly associated $(P<.01)$ with quartiles of CTD, excluding large volume transfusions, and excluding those patients who had undergone previous cardiac surgery, were coenrolled in the ATACAS trial, required CPB duration $>120$ minutes, or underwent surgical re-exploration for bleeding on postoperative day 0 . Additional analyses explored for evidence of subgroup differences in the relationship between hemodynamic parameters and CTD. Finally, we dichotomized each of peak SBP, MAP, and CVP at their upper decile to explore the relationship between relative hemodynamic outliers and previously described outcomes.

In view of the exploratory nature of the analysis a formal sample size calculation was not undertaken. Results of regression analyses are reported as regression coefficients or odds ratios, with $95 \%$ confidence intervals (CIs) expressing the level of uncertainty. Evidence of interaction between subgroups was evaluated using the Wald test. Reporting of results is based on recommendations from the Strengthening the Reporting of
Observational Studies in Epidemiology statement for reporting observational studies. ${ }^{15}$

\section{RESULTS}

After the previously described exclusions, 793 patients remained for the current analysis (Figure 1). Mean patient age was $65 \pm 12$ years, $574(72 \%)$ were men, with surgery deemed elective in 387 patients (49\%). A history of hypertension was noted in 580 (73\%) patients; median preoperative estimated glomerular filtration rate was $78 \mathrm{~mL} / \mathrm{min} /$ $1.73 \mathrm{~m}^{2}$ (IQR, $61-89 \mathrm{~mL} / \mathrm{min} / 1.73 \mathrm{~m}^{2}$ ) mean preoperative hemoglobin concentration was $13.5 \pm 1.7 \mathrm{~g} / \mathrm{dL}$ and $540 \mathrm{pa}-$ tients $(68 \%)$ were noted to have received aspirin within 3 days before surgery. Median duration of CPB was $93 \mathrm{mi}-$ nutes (IQR, 73-117 minutes).

Peak SBP, peak MAP, and CTD data were available for all patients. Peak CVP was missing for 9 patients and these patients were excluded from subsequent analyses using this variable. Mean peak SBP recorded on postoperative day 0 was $125 \pm 15 \mathrm{~mm} \mathrm{Hg}$ (range, $85-200 \mathrm{~mm} \mathrm{Hg}$ ). Mean peak MAP was $83 \pm 9 \mathrm{~mm} \mathrm{Hg}$ (range, $60-128 \mathrm{~mm} \mathrm{Hg}$ ). Mean peak CVP was $12 \pm 4 \mathrm{~mm} \mathrm{Hg}$ (range, 2-30 mm $\mathrm{Hg}$ ). Median CTD for postoperative day 0 was $310 \mathrm{~mL}$ (IQR, 210-450 mL) with median hourly rate $33 \mathrm{~mL} /$ hour (IQR, 23-51 mL/hour). Postoperative transfusion of any pRBC was identified in 142 patients $(17.9 \%)$ with median pRBC volume of $502 \mathrm{~mL}$ (IQR, 257-750 mL) among those who received blood. Unplanned surgical re-exploration for bleeding on postoperative day 0 or 1 was identified in 21 patients $(2.6 \%)$. Patients who underwent surgical reexploration on postoperative day 0 or 1 had greater CTD compared with those who did not (129 mL/hour [IQR, 92$181 \mathrm{~mL} /$ hour] vs $32 \mathrm{ml} /$ hour [IQR, 23-50 mL/hour]; $P=.0001)$. Mean nadir hemoglobin concentration on postoperative day 0 was lower among patients who received pRBC on postoperative day 0 or 1 compared with those who did not $(8.1 \pm 0.9 \mathrm{~g} / \mathrm{dL}$ vs $10.4 \pm 1.5 \mathrm{~g} / \mathrm{dL}$; $P<.0001)$. Eleven patients $(1.4 \%)$ died before hospital discharge.

Gender, operative procedure, and duration of CPB varied across quartiles of CTD with evidence of an inverse relationship between baseline platelet count and increasing quartiles of CTD (Table 1).

Exploration of the relationship between each of peak SBP, MAP, and CVP with the primary outcome of CTD did not support the existence of a clear inflection point and, based on this, hemodynamic parameters were included as linear terms in models. On univariate analysis there was evidence that increasing peak SBP (regression coefficient, $-2.7 \mathrm{~mL} ; 95 \% \mathrm{CI},-4.4$ to $-1.1 ; P=.001$ for each $10 \mathrm{~mm} \mathrm{Hg}$ increase in SBP) and MAP (regression coefficient, $-6.9 \mathrm{~mL} ; 95 \% \mathrm{CI},-9.6$ to $-4.2 ; P<.001$ for each $10 \mathrm{~mm} \mathrm{Hg}$ increase in MAP) were both inversely associated 


\section{Study flow chart}

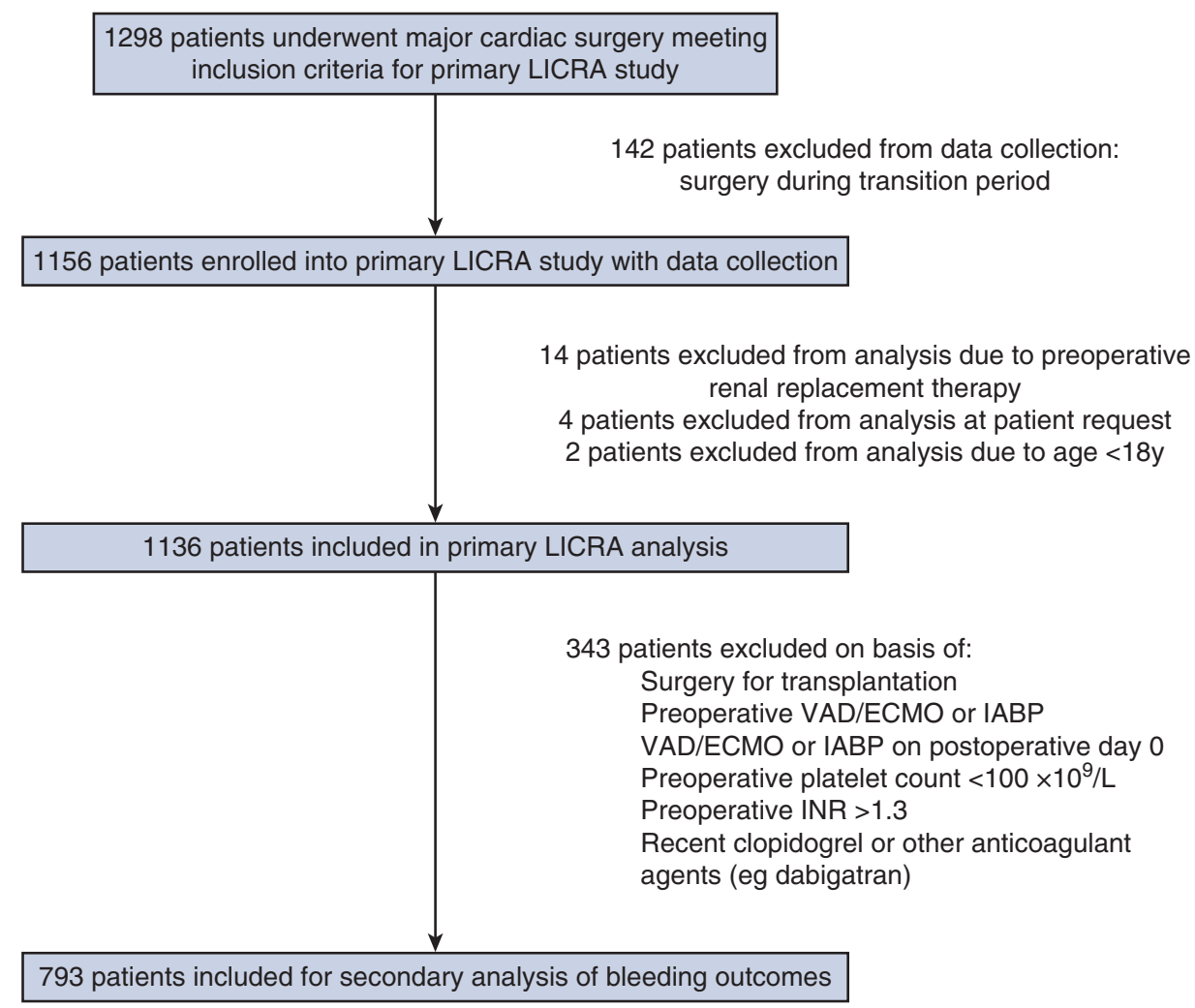

FIGURE 1. Participant flow diagram. The cohort was derived from the previously published Limiting IV Chloride to Reduce AKI (LICRA) controlled clinical trial. VAD/ECMO, Ventricular assist device/extra corporeal membrane oxygenation; IABP, intra-aortic balloon pump; INR, international normalized ratio.

with CTD. There was no evidence of association between peak CVP and CTD (Table 2 and Figures 2-4). There was evidence that increasing peak MAP was associated with a reduced likelihood of receiving a postoperative transfusion of pRBC (OR, 0.95; 95\% CI, 0.93-0.97; $P \leq .001$ for each $1 \mathrm{~mm} \mathrm{Hg}$ increase in peak MAP) and hospital mortality (OR, 0.91; 95\% CI, 0.84-0.99; $P=.03$ for each $1 \mathrm{~mm} \mathrm{Hg}$ increase in peak MAP), whereas increasing peak CVP was associated with an increased likelihood of surgical re-exploration (OR, 1.16; 95\% CI, 1.04-1.28; $P=.01$ for each $1 \mathrm{~mm} \mathrm{Hg}$ increase in CVP).

Adjusted for covariates described earlier both peak SBP and peak MAP were independently and inversely associated with both CTD and any postoperative transfusion of pRBCs (Table 3). Adjusted for covariates there was evidence of an association between increasing peak CVP and postoperative transfusion but not between peak CVP and CTD. Sensitivity analyses did not materially alter interpretation of these results (Tables E1-E3). In subgroup analyses there was no evidence of interaction between peak arterial pressures and operative procedure for the primary outcome of CTD. Weak evidence of interaction between peak arterial blood pressures and coenrollment in the ATACAS trial was of uncertain clinical significance (Figures E1-E3 and Table 4).

To explore for an effect of hemodynamic outliers on bleeding the analysis was repeated after dichotomizing each hemodynamic parameter at the upper decile (peak $\mathrm{SBP}>145 \mathrm{~mm} \mathrm{Hg}$, MAP $>95 \mathrm{~mm} \mathrm{Hg}$, and CVP $>16 \mathrm{~mm}$ $\mathrm{Hg}$ ) and using this as the explanatory variable. The evidence did not support an association between the upper decile of peak SBP or MAP and increased CTD, transfusion, or surgical re-exploration. In contrast, there was evidence that the upper decile of CVP was associated with increased CTD, volume of $\mathrm{pRBC}$ transfused, surgical re-exploration for bleeding, and mortality (Table 4). Peak SBP and peak MAP were positively correlated $(r=0.59 ; P<.0001)$. However, any correlation between peak CVP and either of peak $\operatorname{SBP}(r=-0.08 ; P=.03)$ or peak MAP $(r=-0.07$ $P=.04)$ was weakly negative and of borderline significance.

\section{DISCUSSION}

In a preplanned secondary analysis of a previously published pragmatic trial of perioperative fluid strategies in 
TABLE 1. Baseline characteristics and risk factors according to quartiles of chest tube drainage (CTD) on postoperative day 0

Average CTD on postoperative day 0

Characteristic $\overline{\text { Q1 }(<22.76 \mathrm{~mL} / \mathrm{h}) \text { Q2 (22.78-32.57 } \mathrm{mL} / \mathrm{h}) \text { Q3 }(32.66-51.48 \mathrm{~mL} / \mathrm{h}) \text { Q4 (51.63-382 } \mathrm{mL} / \mathrm{h})}$ value

Preoperative, clinical

Age (y)

Male sex [n, (\%)]

Body mass index

Body surface area $\left(\mathrm{m}^{2}\right)$

History of hypertension $[\mathrm{n},(\%)]$

Coronary artery disease $[\mathrm{n},(\%)]$

Recent myocardial infarction $[\mathrm{n},(\%)]^{*}$

Congestive heart failure $[\mathrm{n},(\%)]$

New York Heart Association functional class $[\mathrm{n},(\%)]$$$
1
$$

2

3

4

Left ventricular ejection fraction (\%)

Diabetes mellitus [n, (\%)]

Peripheral vascular disease [n, $(\%)]$

Current smoker [n, (\%)]†

Chronic obstructive pulmonary disease [n, $(\%)]$

Reoperation [n, (\%)]

Aspirin within $3 \mathrm{~d}$ preoperatively [n, (\%)]

Low molecular weight heparin within

$24 \mathrm{~h}$ preoperatively [n, (\%)]

Case urgency $[\mathrm{n},(\%)]$
Elective
Urgent
Emergent

EuroSCORE $\S$
Preoperative, biochemical
Hemoglobin $(\mathrm{g} / \mathrm{L})$
Platelets $\left(10^{9} / \mathrm{L}\right)$
Activated partial thromboplastin time (sec)
International normalized ratio
Albumin (g/L)
Creatinine $(\mu \mathrm{mol} / \mathrm{L})$
Estimated glomerular filtration rate | $\left(\mathrm{mL} / \mathrm{min} / 1.73 \mathrm{~m}^{2}\right)$
Estimated glomerular filtration rate $<60 \mathrm{~mL} / \mathrm{min} / 1.73 \mathrm{~m}^{2}$ [n, (\%)]
Intraoperative
Operation [n, $(\%)]$
Coronary artery bypass graft on pump
Coronary artery bypass graft off pump
Valve
Valve + coronary artery bypass graft
Valve + other
Aortic root \pm other
Other\#
Cardiopulmonary bypass duration (min)

$\begin{array}{rlrl}64 & \pm 13 & 66 & \pm 12 \\ 124 & \pm 62.3 & 147 & \pm 74.2 \\ 29.8 & \pm 6.5 & 28.9 & \pm 5.7 \\ 1.9 & \pm 0.2 & 2.0 & \pm 0.2 \\ 147 & \pm 73.9 & 149 & \pm 75.3 \\ 132 & \pm 66.3 & 156 & \pm 78.8 \\ 15 & \pm 7.5 & 13 & \pm 6.6 \\ 11 & \pm 5.5 & 13 & \pm 6.6\end{array}$

\begin{tabular}{|c|c|}
\hline $28 \pm 14.1$ & $32 \pm 16.2$ \\
\hline $106 \pm 53.3$ & $98 \pm 49.5$ \\
\hline $61 \pm 30.7$ & $63 \pm 31.8$ \\
\hline $4 \pm 2.0$ & $5 \pm 2.5$ \\
\hline $60(53-60)$ & $60(55-60)$ \\
\hline $68 \pm 34.2$ & $58 \pm 29.3$ \\
\hline $18 \pm 9.1$ & $19 \pm 9.6$ \\
\hline $26 \pm 13.1$ & $23 \pm 11.7$ \\
\hline $32 \pm 16.1$ & $27 \pm 13.6$ \\
\hline $6 \pm 3.0$ & $7 \pm 3.5$ \\
\hline $126 \pm 64.6$ & $134 \pm 69.1$ \\
\hline $25 \pm 12.6$ & $36 \pm 18$ \\
\hline
\end{tabular}

$104 \pm 52.3$

$91 \pm 45.7$

$4 \pm 2.0$

$4.3 \pm 2.6$

$\begin{array}{cc}135 \pm 15 & 136 \pm 17 \\ 251 \pm 76 & 236 \pm 72 \\ 32(30-36) & 33(31-37) \\ 1(1-1.1) & 1(1-1.1) \\ 35 \pm 4 & 35 \pm 5 \\ 81(71-98) & 82(73-96) \\ 80(61-89) & 80(66-90)\end{array}$

$$
\begin{aligned}
104 & \pm 52.5 \\
94 & \pm 47.5 \\
0 & \pm 0.0 \\
4.1 & \pm 2.7
\end{aligned}
$$

$43 \pm 21.7$

$39 \pm 19.7$
$56 \pm 28.3$

$$
\begin{aligned}
65 & \pm 11 \\
146 & \pm 73.7 \\
28.7 & \pm 5.3 \\
2.0 & \pm 0.2 \\
144 & \pm 72.7 \\
155 & \pm 78.3 \\
17 & \pm 8.6 \\
19 & \pm 9.6
\end{aligned}
$$
$30 \pm 15.2$
$105 \pm 53.0$
$55 \pm 27.8$
$8 \pm 4.0$
$60(50-60)$
$61 \pm 30.8$
$22 \pm 11.1$
$20 \pm 10.2$
$28 \pm 14.1$
$7 \pm 3.5$
$141 \pm 71.6$
$38 \pm 19.4$

$$
\begin{aligned}
& 14 \pm 7.1 \\
& 109 \pm 55.1 \\
& 64 \pm 32.3 \\
& 11 \pm 5.6 \\
& 60(53-60) \\
& 53 \pm 26.8 \\
& 27 \pm 13.6 \\
& 28 \pm 14.4 \\
& 34 \pm 17.2 \\
& 11 \pm 5.6 \\
& 139 \pm 70.9 \\
& 43 \pm 21.7 \\
& \\
& 87 \pm 43.9 \\
& 104 \pm 52.5 \\
& 7 \pm 3.5 \\
& 4.7 \pm 3.0
\end{aligned}
$$

.002

.03

.29

.77

.02

.43

.45

.04

.44

.46

.62

.74

.74
.57

.44

.11

.04

$92 \pm 46.5$

$98 \pm 49.5$

$8 \pm 4.0$

$4.2 \pm 3.0$

$135 \pm 18$

$229 \pm 71$

33 (30-37)

1 (1-1.1)

$35 \pm 5$

85 (73-111)

79 (57-90) .20

$134 \pm 17$

$214 \pm 65$

34 (31-38)

1 (1-1.1)

$35 \pm 5$

88 (74-106)

74 (59-87)

.71

$<.0001$

.06

.18

.50

.04

.45

$50 \pm 25.3$

.19

Values for continuous variables are presented as mean \pm standard deviation or median (interquartile range) according to distribution. Values for categorical variables are presented as count (proportion). Significance testing is with analysis of variance, Kruskal-Wallis test, $\chi^{2}$ statistic, Fisher exact test, or nonparametric trend test for ordered categorical variables. CTD, Chest tube drainage; EuroSCORE, European system for cardiac operative risk evaluation. $*<7 \mathrm{~d}$. $\dagger$ Nine patients with unknown smoking status excluded from comparison. †Previous sternotomy. §Additive EuroSCORE calculated within the limits of accuracy of variables recorded by clinicians to reasonably reflect parameters defined on www.euroscore.org. $\|$ Values $>90 \mathrm{~mL} / \mathrm{min} / 1.73 \mathrm{~m}^{2}$ are reported only as $>90$. $\llbracket$ Reported $P$ value is for $\chi^{2}$ test because Stata software was unable to compute Fisher exact test for this $7 \times 4$ table. \#Including 2 thoracoabdominal aortic aneurysm repairs requiring intraoperative extracorporeal circulatory support. 
TABLE 2. Univariate association between hemodynamic variables (systolic blood pressure [SBP], mean arterial pressure [MAP], and central venous pressure $[\mathrm{CVP}]$ ) and bleeding metrics on postoperative day 0

\begin{tabular}{|c|c|c|c|c|c|c|}
\hline \multirow[b]{2}{*}{ Bleeding metric } & \multicolumn{2}{|l|}{ SBP* (mm Hg) } & \multicolumn{2}{|l|}{$\mathbf{M A P} \dagger(\mathbf{m m ~ H g})$} & \multicolumn{2}{|l|}{$\mathbf{C V P}+(\mathbf{m m ~ H g})$} \\
\hline & $\begin{array}{c}10 \mathrm{~mm} \mathrm{Hg} \text { increase } \\
\text { (regression coefficient } \\
[95 \% \mathrm{CI}])\end{array}$ & $\begin{array}{c}P \\
\text { value }\end{array}$ & $\begin{array}{c}10 \mathrm{~mm} \mathrm{Hg} \text { increase } \\
\text { (regression coefficient } \\
[95 \% \mathrm{CI}])\end{array}$ & $\begin{array}{c}P \\
\text { value }\end{array}$ & $\begin{array}{c}1 \mathrm{~mm} \mathrm{Hg} \text { increase } \\
\text { (regression coefficient } \\
[95 \% \mathrm{CI}])\end{array}$ & $\begin{array}{c}P \\
\text { value }\end{array}$ \\
\hline Chest tube drainage $\S(\mathrm{mL} / \mathrm{h})$ & $-2.7(-4.4$ to -1.1$)$ & .001 & $-6.9(-9.6$ to -4.2$)$ & $<.001$ & $0.3(-0.4$ to 1.0$)$ & .34 \\
\hline Chest tube drainage $(\mathrm{mL} / \mathrm{kg} / \mathrm{h})$ & $0(-0.1$ to 0$)$ & .004 & $-0.1(-0.1$ to -0.1$)$ & $<.001$ & $0(0$ to 0$)$ & .40 \\
\hline Postoperative packed red blood cells $\|(\mathrm{mL})$ & $-16(-30$ to -2$)$ & .03 & $-49(-72$ to -26$)$ & $<.001$ & $9(3$ to 15$)$ & .003 \\
\hline \multirow[t]{2}{*}{$\begin{array}{l}\text { Postoperative pRBCs (mL) if volume } \\
\quad<560 \mathrm{~mL} \text { ๆ }\end{array}$} & $-5(-11$ to 1$)$ & .08 & $-13(-23$ to -3$)$ & .01 & $0(-2$ to 3$)$ & .80 \\
\hline & $\begin{array}{l}1 \mathrm{~mm} \text { Hg increase } \\
\text { (odds ratio }[95 \% \mathrm{CI}])\end{array}$ & & $\begin{array}{l}1 \mathrm{~mm} \text { Hg increase } \\
\text { (odds ratio }[95 \% \mathrm{CI}])\end{array}$ & & $\begin{array}{l}1 \mathrm{~mm} \text { Hg increase } \\
\text { (odds ratio }[95 \% \mathrm{CI}])\end{array}$ & \\
\hline Any postoperative packed red blood cells\# & $0.98(0.97$ to 1.00$)$ & .02 & 0.95 (0.93 to 0.97$)$ & $<.001$ & $1.05(1.00$ to 1.10$)$ & .05 \\
\hline $\begin{array}{l}\text { Any postoperative packed red blood cells } \\
\text { if volume }<560 \mathrm{~mL} \text { ฯ }\end{array}$ & $0.99(0.97$ to 1.00$)$ & .07 & $0.96(0.94$ to 0.99$)$ & .01 & $1.02(0.96$ to 1.08$)$ & .49 \\
\hline $\begin{array}{l}\text { Unplanned surgical re-exploration for } \\
\text { bleeding on postoperative day } 0 \text { or } 1^{* *}\end{array}$ & $0.99(0.96$ to 1.02$)$ & .43 & $0.95(0.90$ to 1.00$)$ & .07 & $1.16(1.04$ to 1.28$)$ & .01 \\
\hline Hospital mortality & 0.98 (0.94 to 1.02$)$ & .35 & 0.91 (0.84 to 0.99$)$ & .03 & $1.19(1.04$ to 1.36$)$ & .01 \\
\hline \multicolumn{7}{|c|}{$\begin{array}{l}S B P \text {, Systolic blood pressure; } M A P \text {, mean arterial pressure; } C V P \text {, central venous pressure; } C I \text {, confidence interval. *Second highest SBP recorded between postoperative intensive } \\
\text { care unit admission and midnight on postoperative day } 0 \text { (based on } \mathrm{n}=793 \text { ). } † \text { Second-highest MAP recorded between postoperative intensive care unit admission and midnight on } \\
\text { postoperative day } 0 \text { (based on } \mathrm{n}=793 \text { ). †Second-highest CVP recorded between postoperative intensive care unit admission and midnight on postoperative day } 0 \text {. Nine patients } \\
\text { had no CVP recorded within that period and a further } 5 \text { patients were excluded from analysis of CVP due to recorded value for second highest CVP less than recorded value for } \\
\text { second-lowest CVP within the same time period (based on } \mathrm{n}=779 \text { ). §Chest tube drainage calculated as total daily chest tube drainage recorded in intensive care unit chart/number } \\
\text { of hours from postoperative intensive care unit admission to midnight on postoperative day } 0 \text {. } \| \text { Volume of packed red blood cells administered from postoperative intensive care } \\
\text { unit admission through completion of postoperative day } 1 \text { or intensive care unit discharge, whichever occurred first. } \uparrow \text { Patients transfused }>560 \mathrm{~mL} \text { were excluded from analysis, } \\
\text { leaving } \mathrm{n}=750, \mathrm{n}=750 \text {, and } \mathrm{n}=736 \text { for analysis of peak SBP, peak MAP, and peak CVP, respectively. \#Any administration of packed red blood cells from postoperative } \\
\text { intensive care unit admission through completion of postoperative day } 1 \text { or ICU discharge, whichever occurred first. **Return to operating room before the conclusion of post- } \\
\text { operative day } 1 \text { that, in the opinion of investigators, was both unplanned (ie, excluding open chest cases at the end of index surgery) and due to bleeding. Patients undergoing re- }\end{array}$} \\
\hline
\end{tabular}

patients undergoing cardiac surgery we found no evidence supporting an association between increasing peak SBP or peak MAP postoperatively on the day of surgery and increased CTD or other bleeding-associated complications.

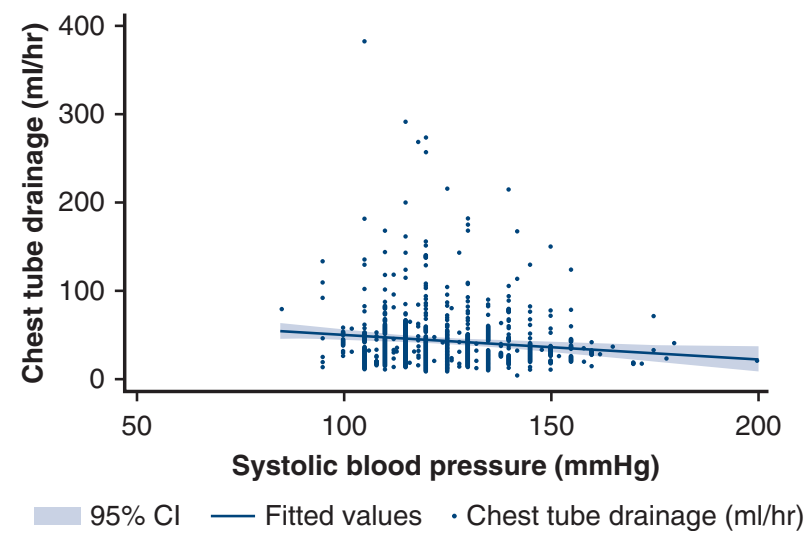

FIGURE 2. Chest tube drainage versus peak systolic blood pressure. Raw values and line-of-best-fit with $95 \%$ confidence interval $(95 \% \mathrm{CI})$. Chest tube drainage measured from time of postoperative intensive care unit admission until midnight on postoperative day 0 . Peak systolic blood pressure was defined by second-highest recorded systolic blood pressure on postoperative day 0 .
Increasing peak CVP was variably associated with increased CTD, pRBC transfusion, surgical reexploration, and mortality. However, there was no positive correlation between peak CVP and peak values of either

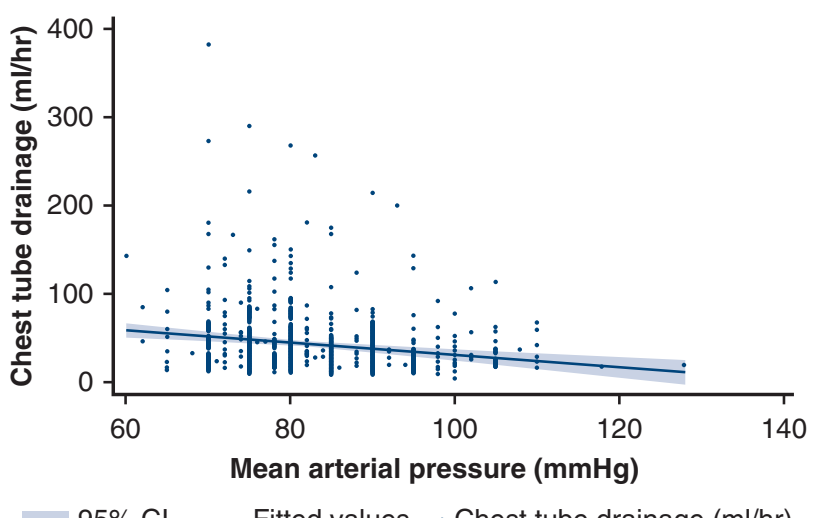

FIGURE 3. Chest tube drainage versus peak mean arterial pressure. Raw values and line-of-best-fit with $95 \%$ confidence interval $(95 \% C I)$. Chest tube drainage measured from time of postoperative intensive care unit admission until midnight on postoperative day 0 . Peak mean arterial pressure was defined by second-highest recorded mean arterial pressure on postoperative day 0 . 


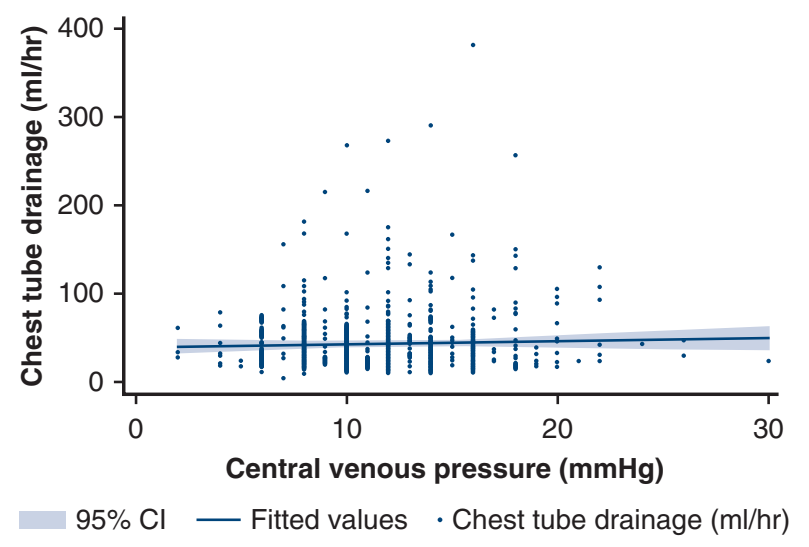

FIGURE 4. Chest tube drainage versus peak central venous pressure. Raw values and line-of-best-fit with $95 \%$ confidence interval $(95 \% \mathrm{CI})$. Chest tube drainage measured from time of postoperative intensive care unit admission until midnight on postoperative day 0 . Peak central venous pressure was defined by second highest recorded central venous pressure on postoperative day 0 .

SBP or MAP. Our data challenges pre-existing assumptions and promotes equipoise for the conduct of clinical trials evaluating a potential end-organ protective effect of higher perioperative blood pressure targets after cardiac surgery.

Narrative reviews suggest that hypertension may increase bleeding, making varied recommendations for postoperative care that include a target MAP of 70 to $80 \mathrm{~mm} \mathrm{Hg},{ }^{16}$ or 60 to $90 \mathrm{~mm} \mathrm{Hg}$ with an SBP target ranging from 90 to $140 \mathrm{~mm} \mathrm{Hg},{ }^{17}$ but with reduced target pressures in the presence of bleeding. However, these recommendations are not supported by published data and any relationship between postoperative blood pressure and bleeding remains poorly characterized. Although it is further suggested that higher pressures may be required to ensure adequate end-organ perfusion in the context of pre-existing hypertension or renal insufficiency, ${ }^{16,17}$ a history of hypertension alone is present at baseline in the majority of patients enrolled in contemporary cardiac surgery trials. ${ }^{14,18-22}$

Recently published retrospective data reports an association between sustained intraoperative hypotension and stroke after cardiac surgery. ${ }^{23}$ However, 2 small trials have yielded conflicting results for the effect of targeting a higher MAP during CPB on postoperative outcomes. ${ }^{24,25}$ The intraoperative period is a relatively brief component of the broader perioperative period and obligate periods of hypotension necessary to facilitate routine aspects of the surgical procedure (eg, aortic cannulation, aortic clamping, and cardiac manipulation) may limit the potential for higher target pressures during this period to optimally influence perioperative outcomes. In contrast, greater difficulty in the rapid identification and correction of excessive bleeding after chest closure and transfer to ICU may temper clinician willingness to trial higher target blood pressures during this potentially important period. Although there are no randomized trial data examining the effect of different target blood pressures through the early postoperative period in patients undergoing cardiac surgery, a recent trial titrating norepinephrine to maintain perioperative SBP within $10 \%$ of baseline intraoperatively and through the first 4 hours postoperatively in patients undergoing noncardiac surgery reported a reduction in adverse outcomes, including AKI and adverse neurologic sequelae $\mathrm{e}^{26}$ and subgroup analyses from a recent trial in critically ill patients with sepsis found that patients with chronic hypertension randomized to a target MAP of 80 to $85 \mathrm{~mm} \mathrm{Hg}$ experienced less renal injury than patients randomized to a target MAP of 65 to $70 \mathrm{~mm} \mathrm{Hg}{ }^{27}$

The current analysis informs an evidence-based discussion of the association between increasing upper levels of blood pressure and metrics of bleeding in a heterogeneous cardiac surgery cohort. We intentionally selected a single value for each of peak SBP, MAP, and CVP as a biologically plausible surrogate for forces acting on potential bleeding sites. Although sustained hypotension may be important for adverse perioperative outcomes reflecting end-organ hypoperfusion, it is biologically plausible that even a relatively brief hypertensive episode may be sufficient to trigger bleeding early after cardiac surgery. Any fall in blood pressure occurring as a result of bleeding would tend to reduce a cumulative time-pressure summary measure of hypertension, potentially masking an important hypertensive exposure. Whereas our preplanned strategy of analyzing a single measure of peak blood pressure limits the potential for a bleeding-related decline in blood pressure to confound our analysis the observational nature of the study combined with temporal uncertainty between peak hemodynamic pressures and bleeding outcomes mean that the current study can only explore for association rather than causation between hemodynamic variables and bleeding and caution must be exercised in the interpretation of our results. Nevertheless, across the range of peak pressures observed, our data did not identify an increase in bleeding with increasing arterial pressure. The level of uncertainty defined by the upper limits of the $95 \%$ CI for the association between both SBP and MAP with CTD, broad internal consistency across outcomes examined using either SBP or MAP, and lack of evidence for an effect of hemodynamic outliers, gives reason to challenge existing assumptions that an increase in postoperative arterial blood pressure is associated with increased bleeding.

The consistent association between increasing peak CVP and outcomes, including transfusion, surgical reexploration, and mortality, in the current cohort warrants consideration. A causal relationship between increasing CVP and venous bleeding provides one potential explanation. However, in contrast to arterial pressure that may decline in response to significant bleeding, the development 
TABLE 3. Multivariate* association between hemodynamic variables (systolic blood pressure [SBP], mean arterial pressure [MAP], and central venous pressure [CVP]) and bleeding metrics on postoperative day 0

\begin{tabular}{|c|c|c|c|c|c|c|}
\hline \multirow[b]{2}{*}{ Bleeding metric } & \multicolumn{2}{|l|}{$\mathbf{S B P}+$} & \multicolumn{2}{|l|}{$\mathbf{M A P}+$} & \multicolumn{2}{|l|}{$\mathbf{C V P} \S$} \\
\hline & $\begin{array}{c}10 \mathrm{~mm} \mathrm{Hg} \text { increase } \\
\text { (regression coefficient } \\
[95 \% \mathrm{CI}])\end{array}$ & $\begin{array}{c}P \\
\text { value }\end{array}$ & $\begin{array}{c}10 \mathrm{~mm} \mathrm{Hg} \text { increase } \\
\text { (regression coefficient } \\
{\left[\begin{array}{lll}95 \% & \mathrm{CI}\end{array}\right]}\end{array}$ & $\begin{array}{c}P \\
\text { value }\end{array}$ & $\begin{array}{c}1 \mathrm{~mm} \mathrm{Hg} \text { increase } \\
\text { (regression coefficient } \\
[95 \% \mathrm{CI}])\end{array}$ & $\begin{array}{c}P \\
\text { value }\end{array}$ \\
\hline Chest tube drainage $\|(\mathrm{mL} / \mathrm{h})$ & $-2.2(-3.9$ to -0.5$)$ & .01 & $-5.3(-8.1$ to -2.6$)$ & $<.001$ & $0.4(-0.3$ to 1.1$)$ & .30 \\
\hline Chest tube drainage $(\mathrm{mL} / \mathrm{kg} / \mathrm{h})$ & $0(-0.1$ to 0$)$ & .01 & $-0.1(-0.1$ to 0$)$ & $<.001$ & $0(0$ to 0$)$ & .44 \\
\hline $\begin{array}{l}\text { Postoperative packed red blood } \\
\text { cells } \uparrow(\mathrm{mL})\end{array}$ & $-15(-29$ to -1$)$ & .04 & $-36(-59$ to -12$)$ & .003 & $9(3$ to 15$)$ & .003 \\
\hline \multirow{2}{*}{$\begin{array}{l}\text { Postoperative } \mathrm{pRBCs}(\mathrm{mL}) \text { if } \\
\text { volume }<560 \mathrm{~mL} \#\end{array}$} & $-7(-13$ to -1$)$ & .03 & $-10(-20$ to 1$)$ & .07 & $1(-2$ to 3$)$ & .59 \\
\hline & $\begin{array}{c}1 \mathrm{~mm} \mathrm{Hg} \text { increase } \\
\text { (odds ratio }[95 \% \mathrm{CI}])\end{array}$ & & $\begin{array}{c}1 \mathrm{~mm} \mathrm{Hg} \text { increase } \\
(\text { odds ratio }[95 \% \mathrm{CI}])\end{array}$ & & $\begin{array}{c}1 \mathrm{~mm} \mathrm{Hg} \text { increase } \\
\text { (odds ratio }[95 \% \mathrm{CI}])\end{array}$ & \\
\hline $\begin{array}{l}\text { Any postoperative packed red } \\
\text { blood cells*** }\end{array}$ & 0.98 (0.96 to 0.99$)$ & .004 & $0.96(0.93$ to 0.98$)$ & .001 & 1.07 (1.01 to 1.13$)$ & .03 \\
\hline $\begin{array}{l}\text { Any postoperative packed red } \\
\text { blood cells if volume }<560 \mathrm{~mL}\end{array}$ & 0.98 (0.96 to 1.00$)$ & .02 & 0.97 (0.95 to 1.00$)$ & .04 & $1.04(0.97$ to 1.11$)$ & .25 \\
\hline \multicolumn{7}{|c|}{ 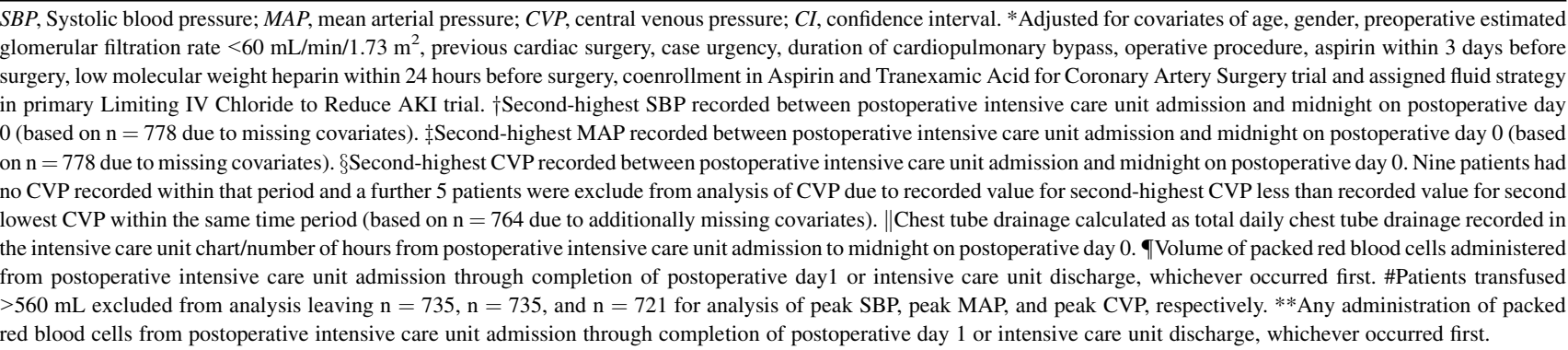 } \\
\hline
\end{tabular}

of hemopericardium as a consequence of bleeding may lead to increasing venous pressures and so confound any association between peak CVP and bleeding. Nevertheless, this remains speculative because our data do not permit an analysis of the temporal relationship between observed pressure and clinical outcome.

Our study has a number of other important strengths and limitations. The preplanned analysis with prospective data collection provided near-complete data for analysis. Using the second-highest SBP, MAP, and CVP sought to eliminate potential confounding by transient pressure increases that may be of uncertain significance, with any inaccuracy from this strategy likely to result in overly conservative estimates for the pressure-bleeding relationship. However, this assumption may be incorrect and the additional complexity of this strategy may have led to inconsistencies in data extraction. Variation in time of day for surgical completion and ICU admission led to a wide range in duration of observation for both bleeding and hemodynamic parameters that may have introduced unrecognized confounding. Our method of checking and correcting perioperative blood transfusion data using product release date from our institutional blood bank will have misclassified some postoperative day 0 transfusions as having occurred intraoperatively and vice-versa and it remains unknown how this may have influenced our results. Small numbers of markedly hypertensive data points limit the precision of estimates for the pressure-bleeding relationship at the upper end of the blood pressure range. Although the transfusion rate of $17.9 \%$ for our cohort was lower than reported for isolated CABG surgery in the Society of Thoracic Surgeons database, our decision to exclude transfusion occurring either intraoperatively or beyond postoperative day 1 aimed to avoid capturing transfusion unlikely to have been related to early postoperative hemodynamic parameters. Although patients with preoperative abnormalities of coagulation were excluded from analysis intraoperative and postoperative coagulation status was not recorded and may represent a source of unrecognized confounding. Additionally, our decision to include certain subgroups of patients who may have an increased baseline bleeding risk (eg aortic surgery) is open to criticism. Greater attention to the avoidance of postoperative hypertension in these patients, or a different relationship between hemodynamics and pressure in these patients may have confounded our results. However, the lack of evidence for interaction between any of case urgency, reoperative surgery or aortic root surgery (each 
TABLE 4. Univariate and multivariate regression analysis of the association between the upper decile of hemodynamic parameters (systolic blood pressure [SBP], mean arterial pressure [MAP], and central venous pressure [CVP]) and metrics of bleeding

\begin{tabular}{|c|c|c|c|c|c|c|}
\hline \multirow[b]{2}{*}{ Bleeding metric } & \multicolumn{2}{|c|}{$\mathrm{SBP}^{*}>145 \mathrm{~mm} \mathrm{Hg}$} & \multicolumn{2}{|c|}{$\mathbf{M A P} \nmid>95$ mm Hg } & \multicolumn{2}{|c|}{$\mathbf{C V P}_{\dagger}^{\dagger}>16 \mathrm{~mm} \mathrm{Hg}$} \\
\hline & $\begin{array}{c}\text { Regression } \\
\text { coefficient } \S \\
(95 \% \text { CI }) \\
\end{array}$ & $P$ value & $\begin{array}{c}\text { Regression } \\
\text { coefficient } \| \\
(95 \% \text { CI })\end{array}$ & $P$ value & $\begin{array}{c}\text { Regression } \\
\text { coefficient } \uparrow \\
(95 \% \text { CI })\end{array}$ & $P$ value \\
\hline Chest tube drainage\# $(\mathrm{mL} / \mathrm{h})$ & $-8.7(-18.0$ to 0.7$)$ & .07 & $-8.8(-18.4$ to 0.8$)$ & .07 & $9.8(0.4$ to 19.2$)$ & .04 \\
\hline Chest tube drainage $(\mathrm{mL} / \mathrm{kg} / \mathrm{h})$ & $-0.1(-0.3$ to 0$)$ & .05 & $-0.1(-0.3$ to 0$)$ & .04 & $0.1(-0.1$ to 0.2$)$ & .35 \\
\hline \multirow[t]{2}{*}{$\begin{array}{l}\text { Postoperative packed red blood } \\
\text { cells** }(\mathrm{mL})\end{array}$} & $-56(-134$ to 23$)$ & .16 & $-67(-148$ to 13$)$ & .10 & 99 (19 to 178$)$ & .02 \\
\hline & $\begin{array}{l}\text { Odds ratio } \\
(95 \% \mathrm{CI})\end{array}$ & & $\begin{array}{l}\text { Odds ratio } \\
(95 \% \mathbf{C I})\end{array}$ & & $\begin{array}{l}\text { Odds ratio } \\
(95 \% \mathrm{CI})\end{array}$ & \\
\hline $\begin{array}{l}\text { Any postoperative packed red } \\
\text { blood cells } \dagger \dagger\end{array}$ & $0.56(0.25$ to 1.26$)$ & .16 & $0.31(0.11$ to 0.88$)$ & .03 & $1.53(0.83$ to 2.83$)$ & .17 \\
\hline $\begin{array}{l}\text { Unplanned return to OR for } \\
\text { bleeding on postoperative } \\
\text { day } 0 \text { or } 1 \neq \ddagger\end{array}$ & $0.58(0.08$ to 4.42$)$ & .60 & $1.32(0.30$ to 5.81$)$ & .71 & $5.11(1.91$ to 13.70$)$ & .001 \\
\hline Hospital mortality & $-\S \S$ & & $-\S \S$ & & $7.13(2.03-25.07)$ & .002 \\
\hline
\end{tabular}

Adjusted for age, gender, previous cardiac surgery, surgical procedure, case urgency, preoperative estimated glomerular filtration rate

$<60 \mathrm{~mL} / \mathrm{min} / 1.73 \mathrm{~m}^{2}$, preoperative exposure to aspirin or low molecular weight heparin, duration of CPB, coenrolment in the Aspirin and Tranexamic Acid for Coronary Artery Surgery trial and original Limiting IV Chloride to Reduce AKI trial period

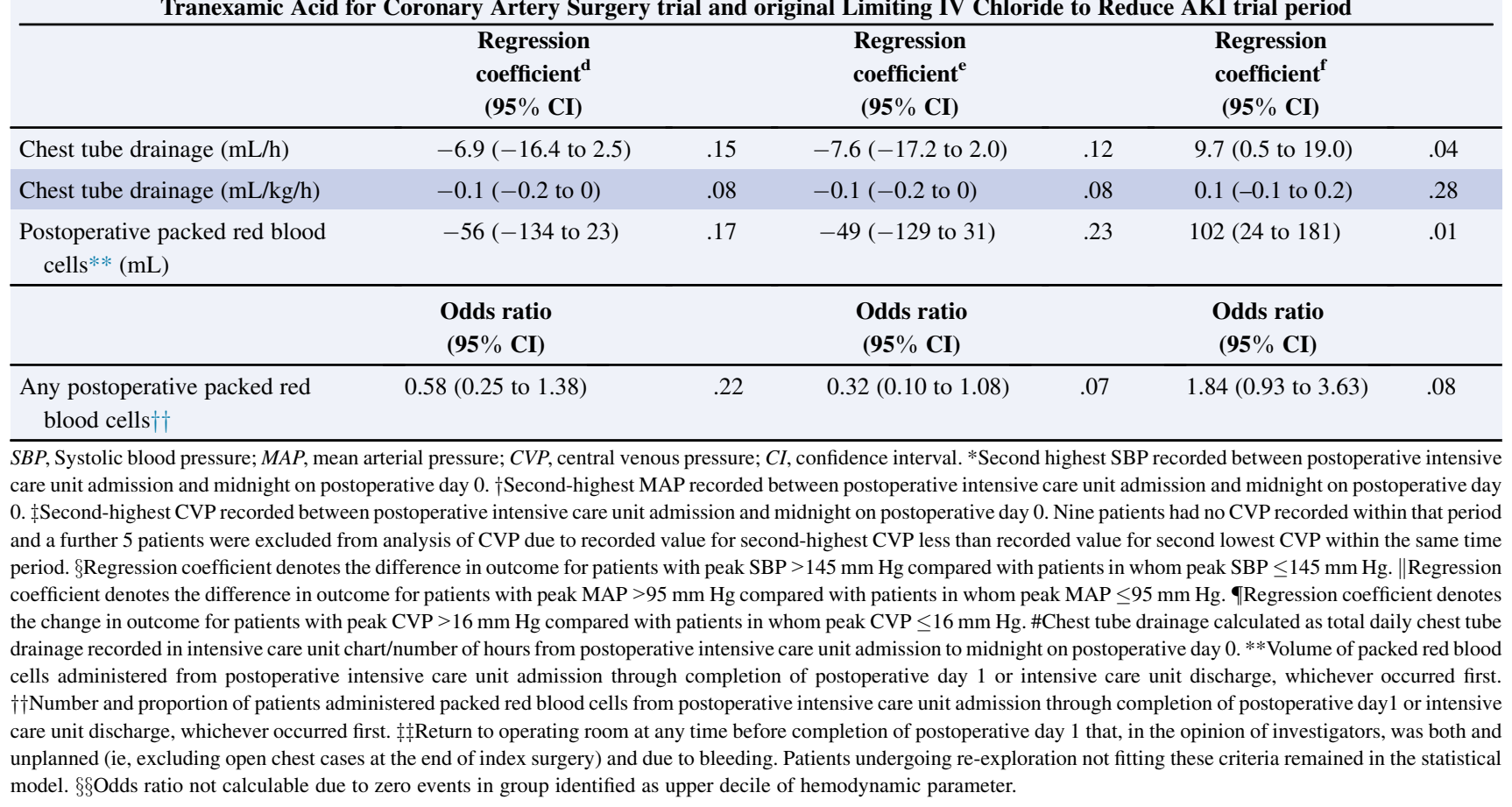

likely identified by clinicians as presenting an increased risk for bleeding) and hemodynamic variables for the outcome of CTD argues against this as an important source of confounding. Moreover, $57 \%$ of patients undergoing "aortic root \pm other" surgery had a history of hypertension, highlighting their potential vulnerability to relative hypotension and associated importance of understanding any association between hemodynamic variables and bleeding. Nevertheless, the exclusion criteria employed mean that our data may not be extrapolated to patients with preoperative bleeding diatheses, those undergoing cardiac transplantation or surgery involving preoperative or postoperative mechanical circulatory support, nor may it be extrapolated to patients where intraoperative surgical judgment identifies an increased risk for perioperative bleeding. Finally, our data cannot 


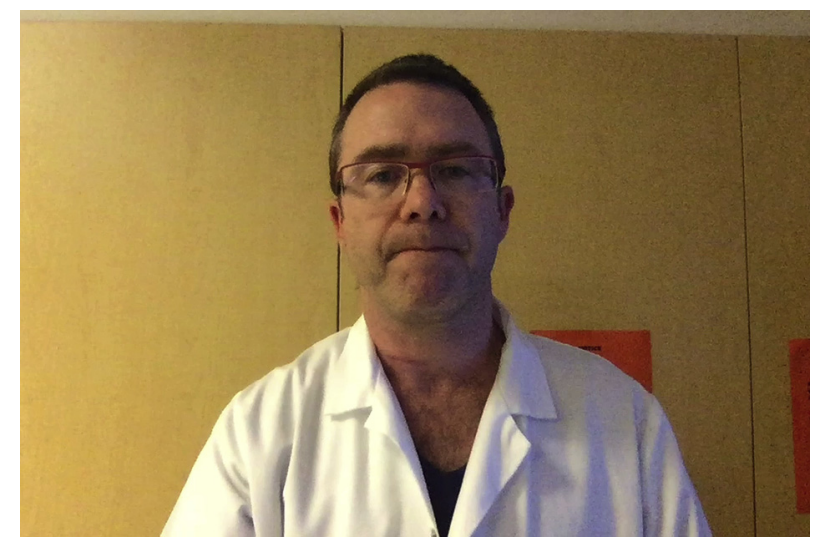

VIDEO 1. Lead investigator Dr David McIlroy explains the importance and relevance of the work. Video available at: https://www.jtcvs.org/ article/S0022-5223(19)30274-0/fulltext.

establish a temporal sequence between hemodynamic indices and metrics of bleeding and the observed relationships must be viewed as association only.

\section{CONCLUSIONS}

The current data did not find any clinically meaningful association between increasing arterial pressure and evidence of increased postoperative bleeding. Within the limitations of our observational data, these findings challenge pre-existing assumptions about the relationship between arterial blood pressure and postoperative bleeding and promote clinical equipoise for the conduct of clinical trials seeking to evaluate a potential end-organ protective effect of higher perioperative blood pressure targets after cardiac surgery (Video 1).

\section{Conflict of Interest Statement}

Authors have nothing to disclose with regard to commercial support.

\section{References}

1. Dasta JF, Kane-Gill SL, Durtschi AJ, Pathak DS, Kellum JA. Costs and outcomes of acute kidney injury (AKI) following cardiac surgery. Nephrol Dial Transplant. 2008;23:1970-4.

2. Garg AX, Devereaux PJ, Yusuf S, Cuerden MS, Parikh CR, Coca SG, et al. Kidney function after off-pump or on-pump coronary artery bypass graft surgery: a randomized clinical trial. JAMA. 2014:311:2191-8.

3. Ricci Z, Cruz D, Ronco C. The RIFLE criteria and mortality in acute kidney injury: a systematic review. Kidney Int. 2007;73:538-46.

4. Robert AM, Kramer RS, Dacey LJ, Charlesworth DC, Leavitt BJ, Helm RE, et al. Cardiac surgery-associated acute kidney injury: a comparison of two consensus criteria. Ann Thorac Surg. 2010;90:1939-43.

5. Aronson S, Phillips-Bute B, Stafford-Smith M, Fontes M, Gaca J, Mathew JP, et al. The association of postcardiac surgery acute kidney injury with intraoperative systolic blood pressure hypotension. Anesthesiol Res Pract. 2013;2013:174091.

6. Kanji HD, Schulze CJ, Hervas-Malo M, Wang P, Ross DB, Zibdawi M, et al. Difference between pre-operative and cardiopulmonary bypass mean arterial pressure is independently associated with early cardiac surgery-associated acute kidney injury. J Cardiothorac Surg. 2010;5:71.
7. Liu YL, Prowle J, Licari E, Uchino S, Bellomo R. Changes in blood pressure before the development of nosocomial acute kidney injury. Nephrol Dial Trans plant. 2009;24:504-11.

8. Brochard L, Abroug F, Brenner M, Broccard AF, Danner RL, Ferrer M, et al. An official ATS/ERS/ESICM/SCCM/SRLF statement: prevention and management of acute renal failure in the ICU patient: an international consensus conference in intensive care medicine. Am J Respir Crit Care Med. 2010;181:1128-55.

9. Joannidis M, Druml W, Forni LG, Groenveld AB, Honore P, Oudemans-van Straaten HM, et al. Prevention of acute kidney injury and protection of renal function in the intensive care unit. Expert opinion of the Working Group for Nephrology, ESICM. Intensive Care Med. 2010;36:392-411.

10. Burke M, Pabbidi MR, Farley J, Roman RJ. Molecular mechanisms of renal blood flow autoregulation. Curr Vasc Pharmacol. 2014;12:845-58.

11. Selnes OA, Gottesman RF, Grega MA, Baumgartner WA, Zeger SL, McKhann GM. Cognitive and neurologic outcomes after coronary-artery bypass surgery. N Engl J Med. 2012;366:250-7.

12. Tarakji KG, Sabik JF III, Bhudia SK, Batizy LH, Blackstone EH. Temporal onset, risk factors, and outcomes associated with stroke after coronary artery bypass grafting. JAMA. 2011;305:381-90.

13. McIlroy D, Murphy D, Kasza J, Bhatia D, Wutzlhofer L, Marasco S. Effects of restricting perioperative use of intravenous chloride on kidney injury in patients undergoing cardiac surgery: the LICRA pragmatic controlled clinical trial. Intensive Care Med. 2017;43:795-806.

14. Myles PS, Smith JA, Forbes A, Silbert B, Jayarajah M, Painter T, et al. Tranexamic acid in patients undergoing coronary-artery surgery. N Engl J Med. 2017; 376:136-48

15. von Elm E, Altman DG, Egger M, Pocock SJ, Gotzsche PC, Vandenbroucke JP The Strengthening the Reporting of Observational Studies in Epidemiology (STROBE) statement: guidelines for reporting observational studies. J Clin Epidemiol. 2008;61:344-9.

16. St Andre AC, DelRossi A. Hemodynamic management of patients in the first 24 hours after cardiac surgery. Crit Care Med. 2005;33:2082-93.

17. Stephens RS, Whitman GJ. Postoperative critical care of the adult cardiac surgical patient. Part I: routine postoperative care. Crit Care Med. 2015;43:1477-97.

18. Lamy A, Devereaux PJ, Prabhakaran D, Taggart DP, Hu S, Paolasso E, et al. Offpump or on-pump coronary-artery bypass grafting at 30 days. $N$ Engl J Med. 2012;366:1489-97

19. Mazer CD, Whitlock RP, Fergusson DA, Hall J, Belley-Cote E, Connolly K, et al Restrictive or liberal red-cell transfusion for cardiac surgery. N Engl J Med. 2017; 377:2133-44.

20. Dieleman JM, Nierich AP, Rosseel PM, can der Maaten JM, Hofland J, Diephuis JC, et al. Intraoperative high-dose dexamethasone for cardiac surgery: a randomized controlled trial. JAMA. 2012;308:1761-7.

21. Whitlock RP, Devereaux PJ, Teoh KH, Lamy A, Vincent J, Pogue J, et al. Methylprednisolone in patients undergoing cardiopulmonary bypass (SIRS): a randomised, double-blind, placebo-controlled trial. Lancet. 2015;386:1243-53.

22. Shroyer AL, Grover FL, Hattler B, Collins JF, McDonald GO, Kozora E, et al On-pump versus off-pump coronary-artery bypass surgery. $N$ Engl $\mathrm{J} \mathrm{Med}$. 2009;361:1827-37.

23. Sun LY, Chung AM, Farkouh ME, van Diepen S, Weinberger J, Bourke M, et al. Defining an intraoperative hypotension threshold in association with stroke in cardiac surgery. Anesthesiology. 2018;129:440-7.

24. Gold JP, Charlson ME, Williams-Russo P, Szatrowski TP, Peterson JC, Pirraglia PA, et al. Improvement of outcomes after coronary artery bypass. A randomized trial comparing intraoperative high versus low mean arterial pressure. J Thorac Cardiovasc Surg. 1995;110:1302-11.

25. Azau A, Markowicz P, Corbeau JJ, Cottineau C, Moreau X, Baufreton C, et al Increasing mean arterial pressure during cardiac surgery does not reduce the rate of postoperative acute kidney injury. Perfusion. 2014;29:496-504.

26. Futier E, Lefrant JY, Guinot PG, Godet T, Lorne E, Cuvillon P, et al. Effect of individualized vs standard blood pressure management strategies on postoperative organ dysfunction among high-risk patients undergoing major surgery: a randomized clinical trial. JAMA. 2017;318:1346-57.

27. Asfar P, Meziani F, Hamel JF, Grelon F, Megarbane B, Anguel N, et al. High versus low blood-pressure target in patients with septic shock. $N$ Engl J Med. 2014;370:1583-93.

Key Words: cardiac surgery, blood pressure, bleeding 


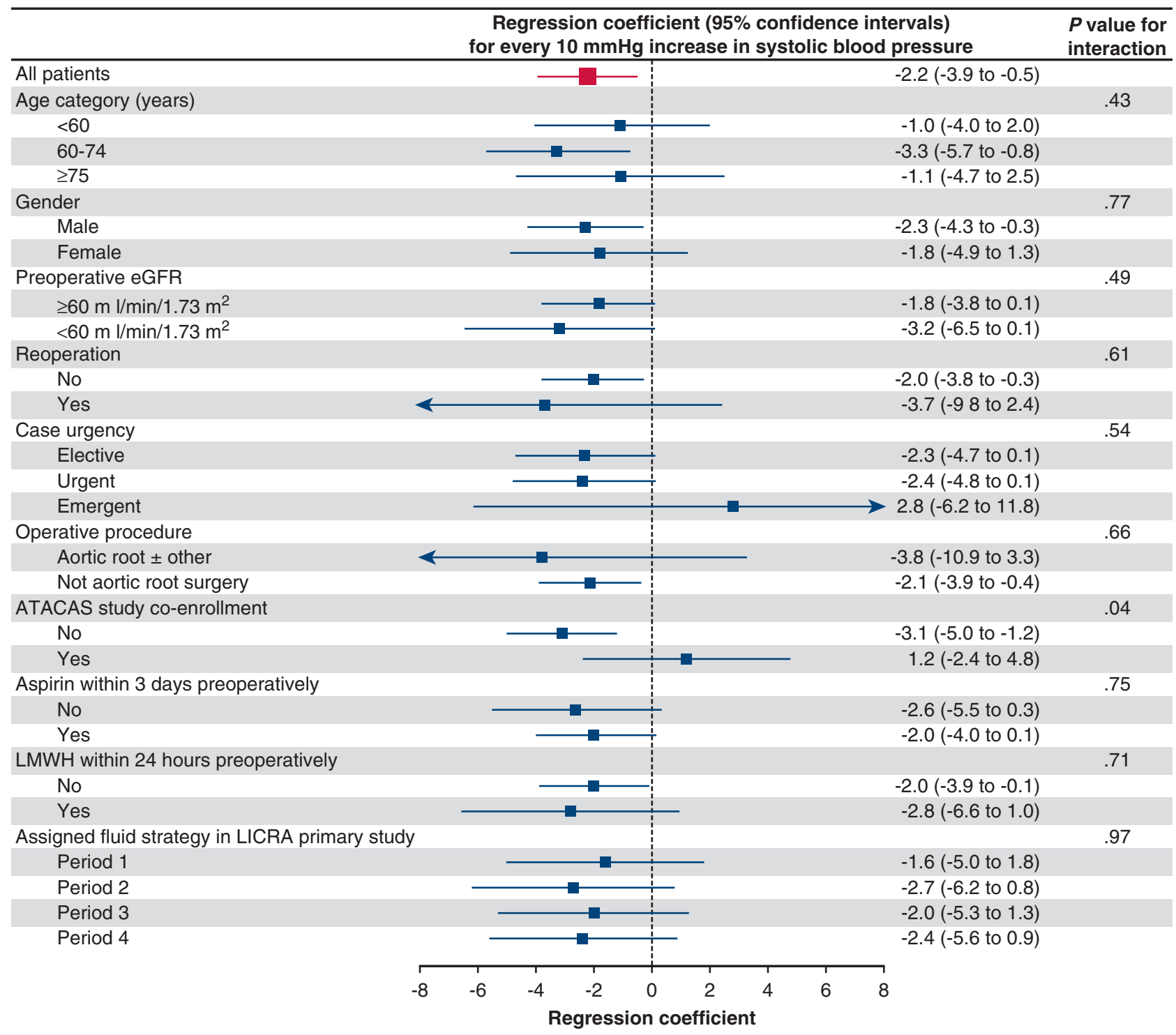

FIGURE E1. Subgroup analysis of regression coefficient for chest tube drainage associated with each $10 \mathrm{~mm} \mathrm{Hg}$ increase in peak systolic blood pressure (SBP). Testing for interaction used the same multivariable model reported in Table 3. In each case, the variable of interest was combined with peak SBP to test for significance. For ease of analysis and interpretation age is analyzed as a 3-level ordinal variable in the test for interaction between age and peak SBP. However, age is included as a continuous term in each of the models testing for interaction between other variables and peak SBP. $e G F R$, Estimated glomerular filtration rate; ATACAS, Aspirin and Tranexamic Acid for Coronary Artery Surgery; LMWH, Low molecular weight heparin; LICRA, Limiting IV Chloride to Reduce AKI. 


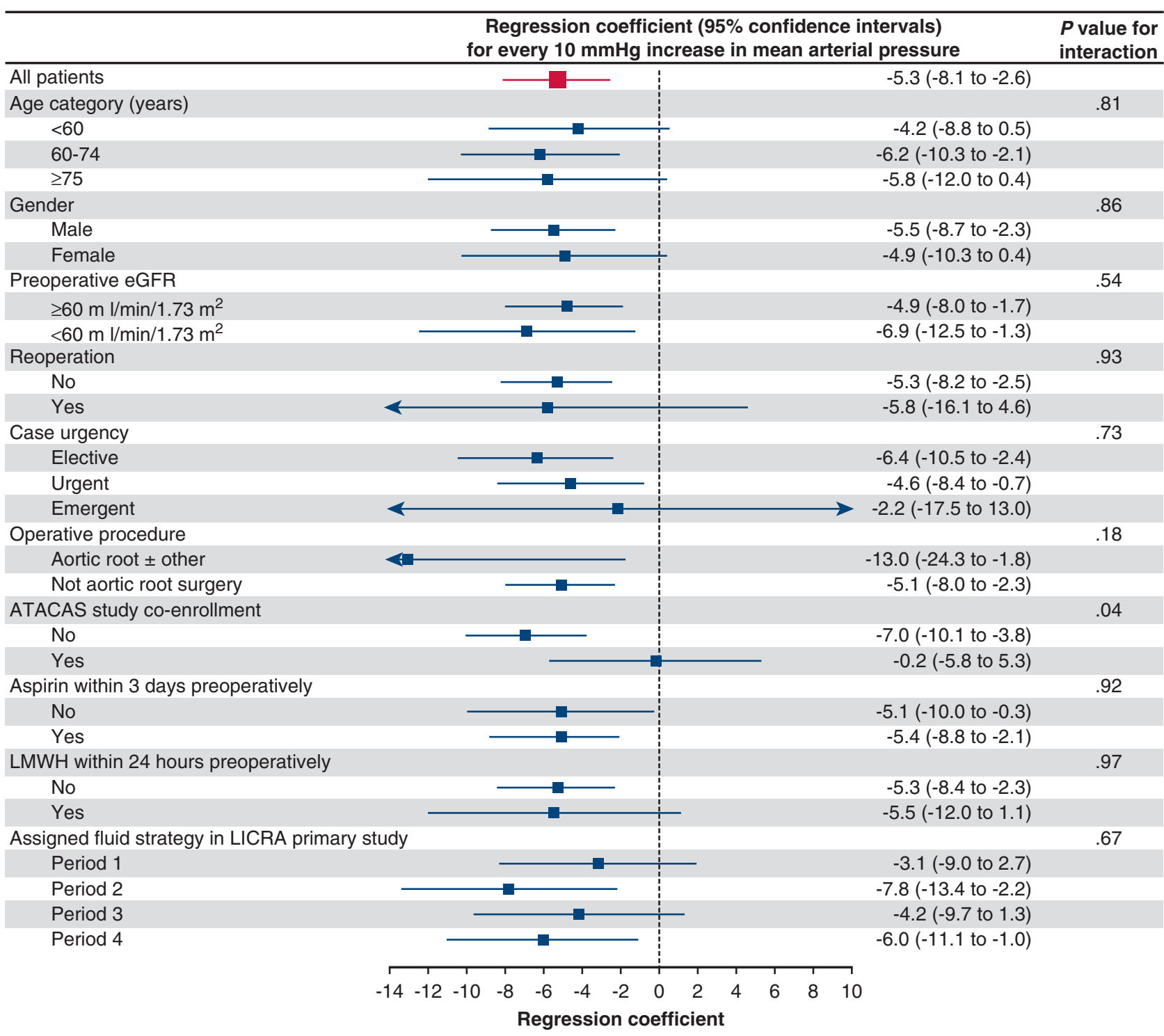

FIGURE E2. Subgroup analysis of regression coefficient for chest tube drainage associated with each $10 \mathrm{~mm} \mathrm{Hg}$ increase in peak mean arterial pressure (MAP). Testing for interaction used the same multivariable model reported in Table 3. In each case, the variable of interest was combined with peak MAP to test for significance. For ease of analysis and interpretation, age is analyzed as a 3-level ordinal variable in the test for interaction between age and peak MAP. However, age is included as a continuous term in each of the models testing for interaction between other variables and peak MAP. $e$ GFR, Estimated glomerular filtration rate; ATACAS, Aspirin and Tranexamic Acid for Coronary Artery Surgery; LMWH, Low molecular weight heparin; LICRA, Limiting IV Chloride to Reduce AKI. 


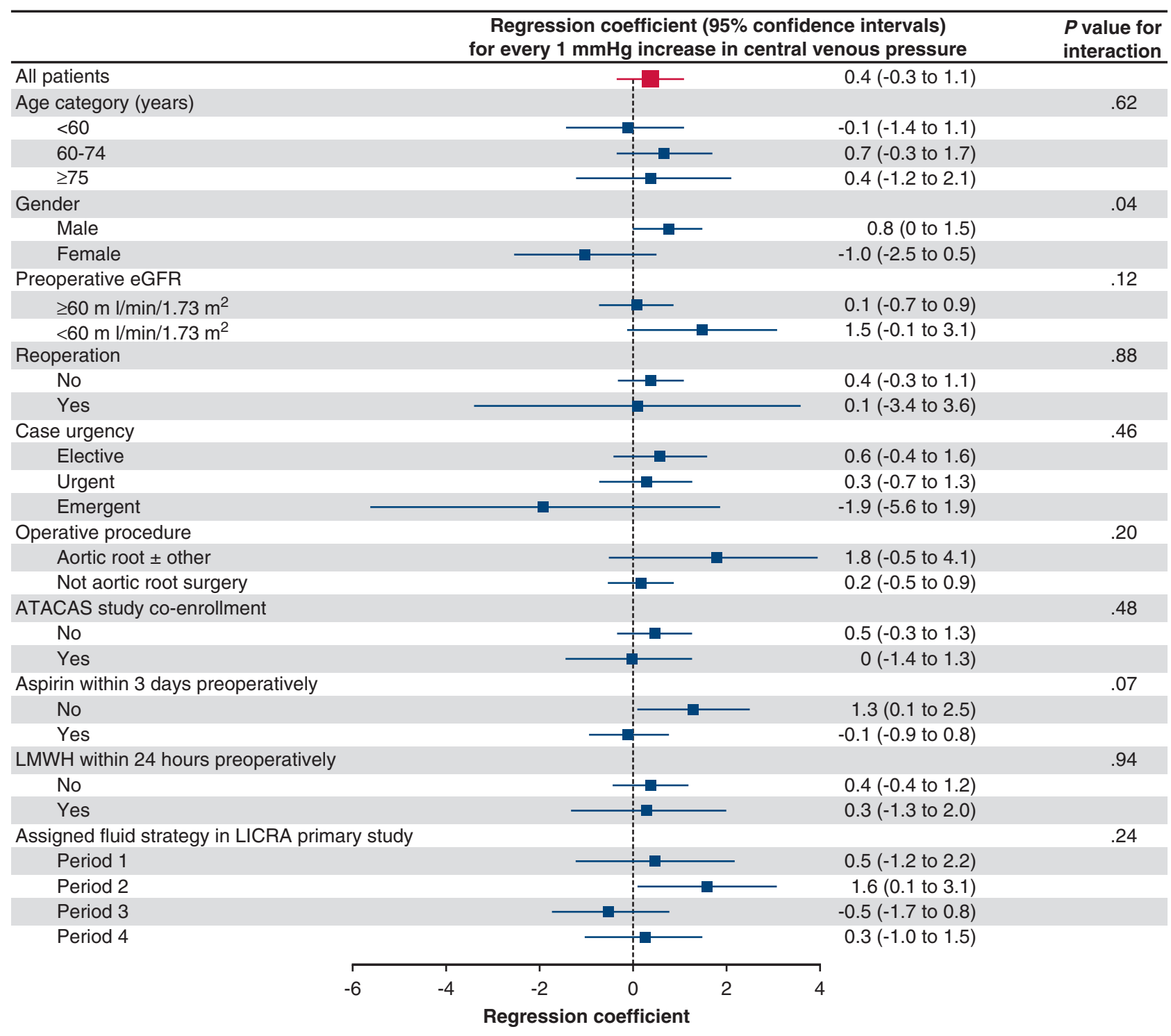

FIGURE E3. Subgroup analysis of regression coefficient for chest tube drainage associated with each $1 \mathrm{~mm} \mathrm{Hg}$ increase in peak central venous pressure (CVP). Testing for interaction used the same multivariable model reported in Table 3. In each case, the variable of interest was combined with peak CVP to test for significance. For ease of analysis and interpretation, age is analyzed as a 3-level ordinal variable in the test for interaction between age and peak CVP. However, age is included as a continuous term in each of the models testing for interaction between other variables and peak CVP. $e G F R$, Estimated glomerular filtration rate; ATACAS, Aspirin and Tranexamic Acid for Coronary Artery Surgery; LMWH, Low molecular weight heparin; LICRA, Limiting IV Chloride to Reduce AKI. 
TABLE E1. Multivariable* association between hemodynamic variables (systolic blood pressure [SBP], mean arterial pressure [MAP], and central venous pressure $[\mathrm{CVP}]$ ) on postoperative day 0 and bleeding metrics, excluding patients undergoing repeat sternotomy or with duration of cardiopulmonary bypass $>\mathbf{1 2 0}$ minutes or enrolled in the Aspirin and Tranexamic Acid for Coronary Artery Surgery trial or with unplanned surgical re-exploration for bleeding on postoperative day 0

\begin{tabular}{|c|c|c|c|c|c|c|}
\hline \multirow[b]{2}{*}{ Bleeding metric } & \multicolumn{2}{|l|}{$\mathbf{S B P} \dagger$} & \multicolumn{2}{|l|}{$\mathbf{M A P} \mathbf{P}_{\ddagger}$} & \multicolumn{2}{|l|}{$\mathbf{C V P} \S$} \\
\hline & $\begin{array}{c}10 \mathrm{~mm} \mathrm{Hg} \text { increase } \\
\text { regression coefficient } \| \\
(95 \% \mathrm{CI})\end{array}$ & $P$ value & $\begin{array}{c}10 \mathrm{~mm} \mathrm{Hg} \text { increase } \\
\text { regression coefficient } \llbracket \\
(95 \% \mathrm{CI})\end{array}$ & $P$ value & $\begin{array}{c}1 \mathrm{~mm} \mathrm{Hg} \text { increase } \\
\text { regression coefficient } \# \\
(95 \% \mathrm{CI})\end{array}$ & $P$ value \\
\hline Chest tube drainage** $(\mathrm{mL} / \mathrm{h})$ & $-2.8(-4.7$ to -0.9$)$ & .004 & $-6.8(-9.9$ to -3.8$)$ & $<.001$ & $0(-0.8$ to 0.8$)$ & $>.99$ \\
\hline \multirow{2}{*}{$\begin{array}{c}\text { Postoperative packed red } \\
\text { blood cells } \dagger \dagger(\mathrm{mL})\end{array}$} & $-11(-22$ to 1$)$ & .08 & $-11(-30$ to 9$)$ & .27 & $3(-2$ to 8$)$ & .23 \\
\hline & $\begin{array}{l}1 \mathrm{~mm} \text { Hg increase } \\
\text { odds ratio }(95 \% \mathrm{CI})\end{array}$ & & $\begin{array}{c}1 \mathrm{~mm} \mathrm{Hg} \text { increase } \\
\text { odds ratio }(95 \% \mathrm{CI})\end{array}$ & & $\begin{array}{l}1 \mathrm{~mm} \text { Hg increase } \\
\text { odds ratio }(95 \% \mathrm{CI})\end{array}$ & \\
\hline $\begin{array}{l}\text { Any postoperative packed } \\
\text { red blood cells } \ddagger \ddagger\end{array}$ & $0.98(0.96$ to 1.00$)$ & .05 & $0.97(0.94$ to 1.01$)$ & .13 & $1.04(0.94$ to 1.14$)$ & .44 \\
\hline \multicolumn{7}{|c|}{ 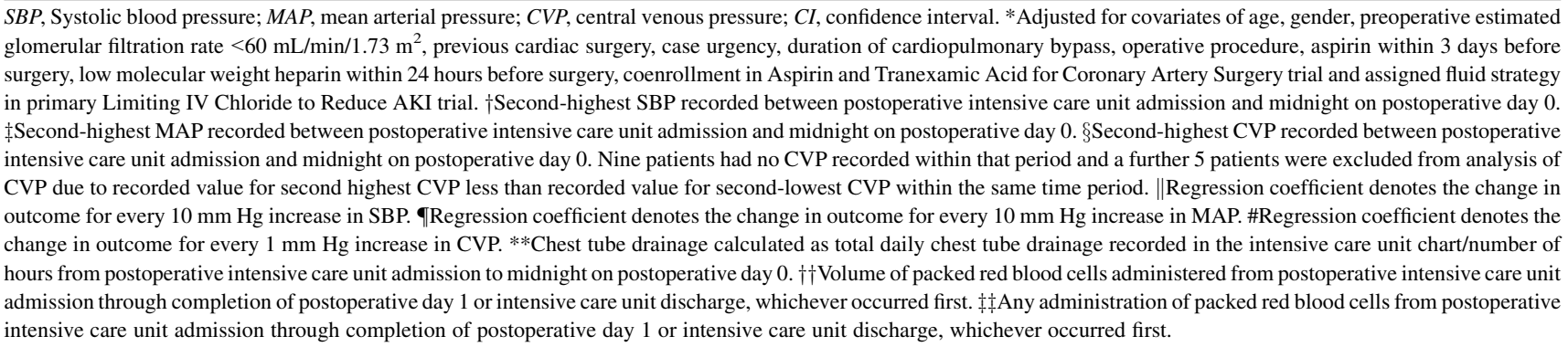 } \\
\hline
\end{tabular}

TABLE E2. Multivariable* association between hemodynamic variables (systolic blood pressure [SBP], mean arterial pressure [MAP], and central venous pressure [CVP]) on postoperative day 0 and bleeding metrics additionally adjusted for preoperative platelet count

\begin{tabular}{|c|c|c|c|c|c|c|}
\hline \multirow[b]{2}{*}{ Bleeding metric } & \multicolumn{2}{|l|}{$\mathbf{S B P}+$} & \multicolumn{2}{|l|}{ MAP ${ }_{\dagger}^{+}$} & \multicolumn{2}{|l|}{$\mathbf{C V P} \wp_{\S}$} \\
\hline & $\begin{array}{c}10 \mathrm{~mm} \mathrm{Hg} \text { increase } \\
\text { regression coefficient } \| \\
(95 \% \mathrm{CI})\end{array}$ & $P$ value & $\begin{array}{l}10 \mathrm{~mm} \mathrm{Hg} \text { increase } \\
\text { regression coefficient } \uparrow \\
(95 \% \mathrm{CI})\end{array}$ & $P$ value & $\begin{array}{c}1 \mathrm{~mm} \text { Hg increase } \\
\text { regression coefficient } \# \\
(95 \% \mathrm{CI})\end{array}$ & $P$ value \\
\hline Chest tube drainage $* *(\mathrm{~mL} / \mathrm{h})$ & $-2.0(-3.7$ to -0.3$)$ & .02 & $-5.3(-8.1$ to -2.6$)$ & $<.001$ & $0.4(-0.3$ to 1.1$)$ & .30 \\
\hline \multirow{2}{*}{$\begin{array}{l}\text { Postoperative packed red } \\
\text { blood cells } \dagger \dagger(\mathrm{mL})\end{array}$} & $-15(-29$ to -1$)$ & .04 & $-36(-59$ to -12$)$ & .003 & $9(3$ to 15$)$ & .003 \\
\hline & $\begin{array}{c}1 \mathrm{~mm} \mathrm{Hg} \text { increase } \\
\text { odds ratio }(95 \% \mathrm{CI})\end{array}$ & & $\begin{array}{c}1 \mathrm{~mm} \mathrm{Hg} \text { increase } \\
\text { odds ratio }(95 \% \mathrm{CI})\end{array}$ & & $\begin{array}{l}1 \mathrm{~mm} \mathrm{Hg} \text { increase } \\
\text { odds ratio }(95 \% \mathrm{CI})\end{array}$ & \\
\hline $\begin{array}{l}\text { Any postoperative packed } \\
\text { red blood cells } \ddagger \ddagger\end{array}$ & 0.98 (0.96 to 0.99$)$ & .003 & $0.96(0.93$ to 0.98$)$ & .001 & 1.07 (1.01 to 1.13 ) & .03 \\
\hline \multicolumn{7}{|c|}{ 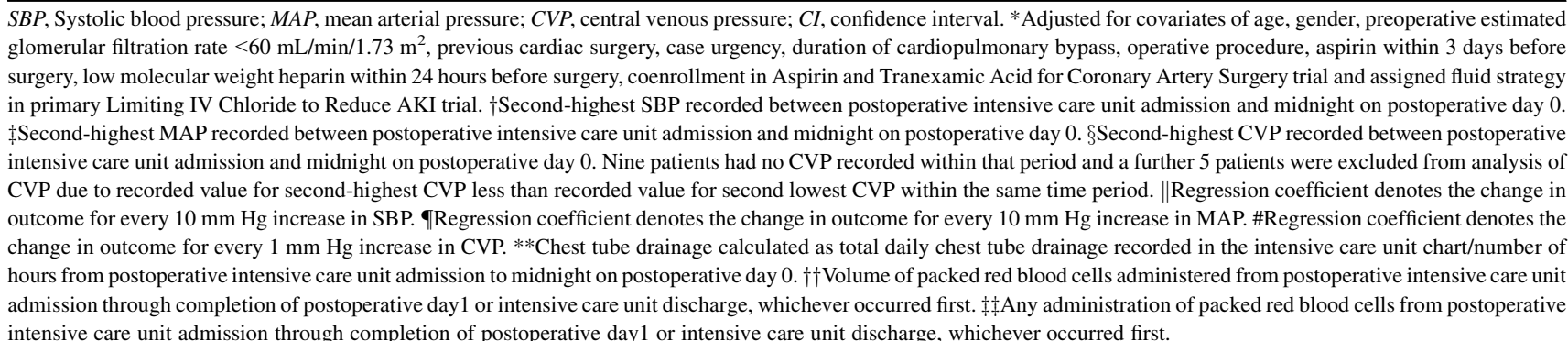 } \\
\hline
\end{tabular}


TABLE E3. Multivariable* association between hemodynamic variables on postoperative day 0 and transfusion outcomes additionally adjusted for preoperative hemoglobin concentration and nadir intraoperative hemoglobin concentration

\begin{tabular}{|c|c|c|c|c|c|c|}
\hline \multirow[b]{2}{*}{ Transfusion outcome } & \multicolumn{2}{|c|}{ Systolic blood pressure $\dagger$} & \multicolumn{2}{|c|}{ Mean arterial pressure } & \multicolumn{2}{|c|}{ Central venous pressure $\S$} \\
\hline & $\begin{array}{c}10 \mathrm{~mm} \mathrm{Hg} \text { increase } \\
\text { regression coefficient } \| \\
(95 \% \mathrm{CI})\end{array}$ & $P$ value & $\begin{array}{c}10 \mathrm{~mm} \text { Hg increase } \\
\text { regression coefficient } \Phi \\
(95 \% \mathrm{CI}) \\
\end{array}$ & $P$ value & $\begin{array}{c}1 \mathrm{~mm} \mathrm{Hg} \text { increase } \\
\text { regression coefficient } \# \\
(95 \% \mathrm{CI}) \\
\end{array}$ & $P$ value \\
\hline \multirow[t]{2}{*}{$\begin{array}{l}\text { Postoperative packed red } \\
\text { blood cells** }(\mathrm{mL})\end{array}$} & $-19(-33$ to -6$)$ & .01 & $-34(-57$ to -12$)$ & .003 & $10(4$ to 15$)$ & .001 \\
\hline & $\begin{array}{l}1 \mathrm{~mm} \text { Hg increase } \\
\text { odds ratio }(95 \% \mathrm{CI})\end{array}$ & & $\begin{array}{c}1 \mathrm{~mm} \mathrm{Hg} \text { increase } \\
\text { odds ratio }(95 \% \mathrm{CI})\end{array}$ & & $\begin{array}{c}1 \mathrm{~mm} \mathrm{Hg} \text { increase } \\
\text { odds ratio }(95 \% \mathrm{CI})\end{array}$ & \\
\hline $\begin{array}{l}\text { Any postoperative packed } \\
\text { red blood cells } \dagger \dagger\end{array}$ & 0.97 (0.96 to 0.99$)$ & .001 & $0.96(0.93$ to 0.98$)$ & .001 & 1.08 (1.02 to 1.15$)$ & .01 \\
\hline \multicolumn{7}{|c|}{ 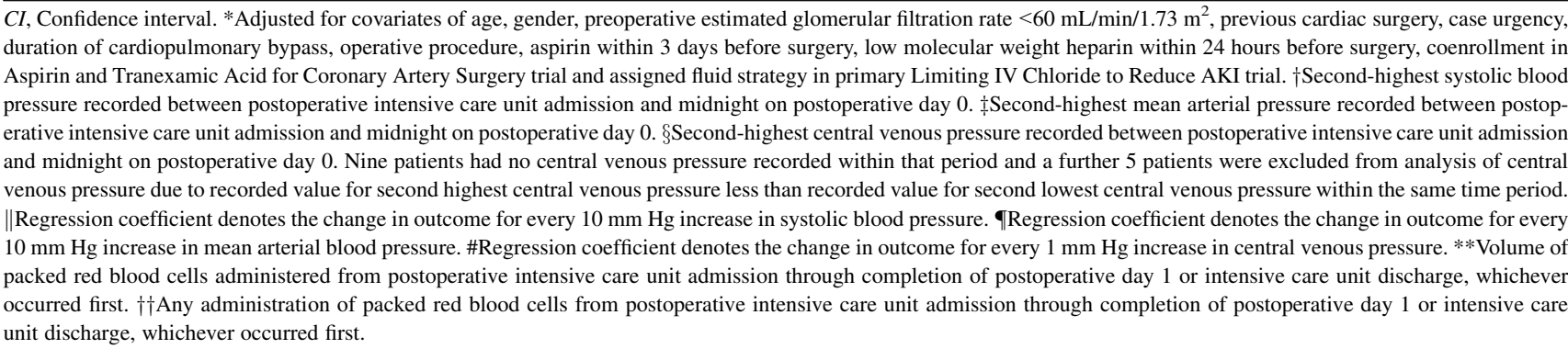 } \\
\hline
\end{tabular}


TABLE E4. Subgroup analysis of regression coefficient for chest tube drainage according to specific type of surgery*

\begin{tabular}{lcc}
\hline \multicolumn{1}{c}{ Variable } & $\begin{array}{c}\text { Regression coefficient } \\
\text { (95\% CI) for every } \\
\mathbf{1 0 ~} \mathbf{~ m m} \text { Hg increase in } \\
\text { systolic blood pressure }\end{array}$ & $\begin{array}{c}\boldsymbol{P} \text { value for } \\
\text { interaction }\end{array}$ \\
\hline All patients & $-2.2(-3.9$ to -0.5$)$ & \\
Operative procedure & & .25 \\
CABG on pump & $-1.9(-4.1$ to 0.3$)$ & \\
CABG off pump & $-8.7(-22.7$ to 5.4$)$ & \\
Valve & $-1.7(-6.0$ to 2.5$)$ & \\
Valve + CABG & $1.0(-4.5$ to 6.6$)$ & \\
Valve + other & $-12.9(-21.9$ to -3.9$)$ & \\
Aortic root \pm other & $-3.8(-10.9$ to 3.3$)$ & \\
Other & $-1.7(-7.8$ to 4.5$)$ \\
\hline
\end{tabular}

Regression coefficient

$(95 \%$ CI) for every

$10 \mathrm{~mm} \mathrm{Hg}$ increase in

mean arterial pressure

\begin{tabular}{ll}
\hline All patients & $-5.3(-8.1$ to -2.6$)$ \\
Operative procedure & \\
CABG on pump & $-5.0(-8.5$ to -1.5$)$ \\
CABG off pump & $-7.7(-25.8$ to 10.4$)$ \\
Valve & $-3.2(-10.4$ to 4.0$)$ \\
Valve + CABG & $2.5(-7.8$ to 12.8$)$ \\
Valve + other & $-27.5(-44.5$ to -10.5$)$ \\
Aortic root \pm other & $-13.0(-24.2$ to -1.8$)$ \\
Other & $-4.9(-15.0$ to 5.1$)$ \\
\hline
\end{tabular}

Regression coefficient

(95\% CI) for every $1 \mathrm{~mm} \mathrm{Hg}$

increase in central venous

pressure

\begin{tabular}{lc}
\hline All patients & $0.4(-0.3$ to 1.1$)$ \\
Operative procedure & \\
CABG on pump & $-0.1(-1.0$ to 0.8$)$ \\
CABG off pump & $1.1(-4.4$ to 6.6$)$ \\
Valve & $0.9(-0.7$ to 2.5$)$ \\
Valve + CABG & $-1.4(-3.8$ to 1.1$)$ \\
Valve + other & $12.1(6.1$ to 18.1$)$ \\
Aortic root \pm other & $1.8(-0.5$ to 4.1$)$ \\
Other & $0.4(-3.2$ to 4.0$)$ \\
\hline
\end{tabular}

$95 \% C I, 95 \%$ confidence interval; $C A B G$, coronary artery bypass grafting. *Testing for interaction used the same multivariable model reported in Table 3. In each case, the variable for operative type was sequentially combined with peak systolic blood pressure, peak mean arterial pressure, and peak central venous pressure to test for significance. 